\title{
The role of ion channels and transporters in cell proliferation and cancer
}

\author{
Andrea Becchetti ${ }^{1 *}$, Luca Munaron ${ }^{2}$ and Annarosa Arcangeli ${ }^{3}$ \\ ${ }^{1}$ Department of Biotechnology and Biosciences, University of Milano-Bicocca, Milano, Italy \\ 2 Department of Life Sciences and Systems Biology, University of Torino, Turin, Italy \\ ${ }^{3}$ Department of Experimental and Clinical Medicine, University of Florence, Florence, Italy \\ *Correspondence: andrea.becchetti@unimib.it
}

Edited by:

Mario L. Diaz, Universidad de La Laguna, Spain

Keywords: ion channels, cell cycle, proliferation, cancer, ion transporters

After the early wavering steps tracing back to at least the 1960's (Cone, 1974; Binggeli and Cameron, 1980), the study of ion transport in cell proliferation and neoplasia is on its way to become a mature research field (Arcangeli et al., 2009). Wide evidence is now available about the regulatory roles exerted by ion channels and transporters on the cell cycle phases (Becchetti, 2011) and other aspects of cell physiology that shape the multistep neoplastic progression, such as resistance to apoptosis (Lehen'kyi et al., 2011), cell invasiveness (Becchetti and Arcangeli, 2010), and angiogenesis (Fiorio Pla et al., 2012). Ion transport is implicated in these cell functions in many ways, from the classic mechanisms relating membrane potential $\left(\mathrm{V}_{\mathrm{m}}\right)$ to $\mathrm{Ca}^{2+}$ homeostasis, to the control of $\mathrm{pH}$, cell volume, growth factor release, interaction with the extracellular matrix, and so forth. Some of these actions probably occur through non-conductive mechanisms, such as intrinsic enzyme activity or conformational coupling with other membrane proteins (e.g., Arcangeli and Becchetti, 2006; Hegle et al., 2006). A major function of ion channels is to mediate the cell interaction with its environment. In the case of cancer cells, the interaction with the tumor milieu' has relevant implications for therapy (Arcangeli, 2011).

The Research Topic Issue on Ion Transport in Cell Cycle and Cancer addresses classic issues in the field as well as it points to novel perspectives. One example of the latter is the role of $\mathrm{Ca}^{2+}$ in autophagy (Rizzuto et al., 2012), which has not received as much attention as $\mathrm{Ca}^{2+}$ signaling in the cell cycle machinery and apoptosis (Roderick and Cook, 2008; Munaron, 2012). As discussed by Kondratskyi et al. (2013), modulating autophagy has a great potential in cancer diagnosis and treatment. The review discusses the related $\mathrm{Ca}^{2+}$-dependent mechanisms and their meaning in the context of cancer progression and therapy. The role of $\mathrm{Ca}^{2+}$ in autophagy is related to the increasing recognition of the multiple functions of intracellular ion channels, which regulate ion transport across the membranes of cellular organelles. Leanza et al. (2013) provide an updated overview of the role of ion channels in mitochondria, endoplasmic reticulum, nucleus, endosomes, and lysosomes, with special attention to the implications for the biology of cancer.

A general picture of the role of $\mathrm{V}_{\mathrm{m}}$ in cell proliferation and differentiation is provided by Yang and Brackenbury (2013), with a special focus on voltage-gated channels. The paper reviews what is known about the $V_{m}$ changes during cell cycle and the implications of different types of ion channels in the cell cycle stages, cancer cell migration and the differentiation of cancer stem cells. That a wide variety of ion channel types affect the main hallmarks of cancer is also suggested by Crottès et al. (2013), who focus on the role of the sigma- 1 receptor (Sig1R) in cancer cells. Sig1R is a stress-activated chaperone associated with both the plasma membrane and the interface between the mitochondria and the endoplasmic reticulum. Sig1R is often expressed in tumors and several lines of evidence suggest that it is implicated in regulating $\mathrm{Ca}^{2+}$ homeostasis as well as some of the major types of ion channels. The authors suggest that Sig1R contributes to regulate the ion channel expression and function in cancer cells in response to environmental signals.

Following the lead of the seminal studies in lymphocytes (DeCoursey et al., 1984) and early embryos (Day et al., 1993), $\mathrm{K}^{+}$ channels continue to have the lion's share in the field. An overview of the general role exerted by $\mathrm{K}^{+}$channels in cell cycle progression is provided by Ouadid-Ahidouch and Ahidouch (2013), whereas the specific contribution of the voltage-gated $\mathrm{K}_{\mathrm{V}} 1.3$ and $\mathrm{K}_{\mathrm{V}} 1.5$ channels in human cancer is reviewed by Comes et al. (2013). A group of voltage-gated $\mathrm{K}^{+}$channels frequently found to be involved in cancerogenesis comprises the ether-à-go-go $\left(\mathrm{K}_{\mathrm{V}} 10\right.$ or Eag; Pardo and Stühmer, 2008) and ether-à-go-go-related ( $\mathrm{K}_{\mathrm{V}} 11$ or Erg; Arcangeli, 2005) subtypes, whose cell biology is under intense investigation. In this issue, Herrmann et al. (2013) show that the surface expression of the oncogenic $\mathrm{K}_{\mathrm{V}} 10.1$ channel is regulated by the Golgi-resident protein PIST (also known as GOPC), by an interaction mediated by PDZ domain.

In addition, growing evidence points to the role of ligandgated channels in cancer cells. In particular, the nicotinic acetylcholine receptors (nAChRs) are homo- or heteropentamers of $\alpha$ and $\beta$ subunits. These were originally identified in the nervous system, but are now increasingly recognized to be widely expressed outside the nervous system (Egleton et al., 2008; Schuller, 2009; Ambrosi and Becchetti, 2013). Thus, Improgo et al. (2013) discuss the role of the nAChR genes in lung cancer and propose an interesting mechanism whereby signaling mediated by $\alpha 3 / \alpha 5 / \beta 4$-containing nAChRs (which genome-wide analyses correlate with increased smoking dependence and risk of developing lung tumors) promote carcinogenesis in small cell lung carcinoma cells.

Another central aspect of the function of normal and neoplastic cells is the regulation of cell volume, as reviewed by Pedersen et al. (2013). This applies especially to the secretive and absorbing 
epithelia, in which the massive transport of ions, organic compounds, and fluid must be tightly matched to the control of cell volume. Such regulatory processes are generally disrupted in cancer cells and the general oncologic relevance of these observations turns on the fact that most cancers derive from epithelial cells. The authors give a thorough overview of the interaction between the tumor microenvironment and the altered regulation of ion transport. Moreover, they discuss the role of cell volume in cell proliferation and apoptosis, and the involvement of ion transport in tumor drug resistance, with special focus on the implication of chloride, calcium, and $\mathrm{pH}$ regulation.

A key step of the neoplastic progression is the regulation of cell migration, whose derangement is implicated in the metastatic cascade (Becchetti and Arcangeli, 2010) and tumor vascularization (Fiorio Pla et al., 2012). Some subtypes of the Transient Receptor Potential (TRP) channels have been found to participate to the regulation of cell migration, as is reviewed by Fiorio Pla and Gkika (2013). The authors especially focus on the implication of TRP channels in cell migration during the neoplastic progression. A different and novel aspect of the regulation of cancer cell migration is the implication of the tumor-associated carbonic anhydrase IX (CA IX) on focal contacts during cell spreading and migration. CA IX provides intracellular bicarbonate and extracellular $\mathrm{H}^{+}$to support cancer cell survival and invasiveness and is the only human CA isoform containing an extracellular proteoglycan domain (Monti et al., 2012). In their paper, Csaderova et al. (2013) show the regulatory interaction of CA IX with the focal contact sites, and provide the first evidence that CA IX localizes in the focal adhesion structures.

Several of the above papers describe the potential therapeutic applications of targeting specific ion channels and transporters. Cancer treatment is however more specifically addressed by Huber et al. (2013), who illustrate the use of ionizing radiation. This causes double-strand DNA breakages and thus cancer cell death, but also targets the plasma membrane. The ensuing modifications of ion channels and transporters can contribute to the survival of the irradiated cells. The authors discuss what is known about the mechanisms of the radioresistance dependent on ion transporters and suggest possible ways to make tumor cells more sensitive to radiation by proper targeting of ion channels and transporters.

Besides illustrating some of the hot topics in the field, the papers of the present Research Topic Issue constitute a most useful introduction to a literature that has already become too vast to be mastered by a single investigator.

\section{REFERENCES}

Ambrosi, P., and Becchetti, A. (2013). Targeting neuronal nicotinic receptors in cancer: new ligands and potential side-effects. Recent Pat. Anticancer Drug Discov. 8, 38-52.

Arcangeli, A. (2005). Expression and role of hERG channels in cancer cells. Novartis Found. Symp. 266, 225-232. doi: 10.1002/047002142X. ch17

Arcangeli, A. (2011). Ion channels and transporters in cancer. 3. Ion channels in the tumor cell-microenvironment cross talk. Am. J. Physiol. Cell Physiol. 301, C762-C771. doi: 10.1152/ajpcell.00113.2011

Arcangeli, A., and Becchetti, A. (2006). Complex functional interaction between integrin receptors and ion channels. Trends Cell Biol. 16, 631-639. doi: 10.1016/j.tcb.2006.10.003
Arcangeli, A., Crociani, O., Lastraioli, E., Masi, A., Pillozzi, S., and Becchetti, A. (2009). Targeting ion channels in cancer: a novel frontier in antineoplastic therapy. Curr. Med. Chem. 16, 66-93. doi: 10.2174/09298670978700 2835

Becchetti, A. (2011). Ion channels and transporters in cancer. 1. Ion channels and cell proliferation in cancer. Am. J. Physiol. Cell Physiol. 301, C255-C265. doi: 10.1152/ajpcell.00047.2011

Becchetti, A., and Arcangeli, A. (2010). Integrins and ion channels in cell migration: implications for neuronal development, wound healing and metastatic spread. Adv. Exp. Med. Biol. 674, 107-123. doi: 10.1007/978-1-4419-6066-5_10

Binggeli, R., and Cameron, I. L. (1980). Cellular potentials of normal and cancerous fibroblasts and hepatocytes. Cancer Res. 40, 1830-1835.

Comes, N., Bielanska, J., Vallejo-Gracia, A., Serrano-Albarras, A., Marruecos, L., Gómez, D., et al. (2013). The voltage-dependent $\mathrm{K}^{+}$channels Kv1.3 and Kv1.5 in human cancer. Front. Physiol. 4:283. doi: 10.3389/fphys.2013.00283

Cone, C. D. (1974). The role of the surface electric transmembrane potential in normal and malignant mitogenesis. Ann. NY Acad. Sci. 238, 420-435. doi: 10.1111/j.1749-6632.1974.tb26808.x

Crottès, D., Guizouan, H., Martin, P., Borgese, F., and Soriani, O. (2013). The sigma-1 receptor: a regulator of cancer cell electrical plasticity? Front. Physiol. 4:175. doi: 10.3389/fphys.2013.00175

Csaderova, L., Debreova, M., Radvak, P., Stano, M., Vrestiakova, M., Kopacek, J., et al. (2013). The effect of carbonic anhydrase IX on focal contacts during cell spreading and migration. Front. Physiol. 4:271. doi: 10.3389/fphys.2013. 00271

Day, M. L., Pickering, M. J., Johnson, M. H., and Cook, D. I. (1993). Cell cycle control of a large conductance $\mathrm{K}^{+}$channel in mouse early embryos. Nature 365, 560-562. doi: 10.1038/365560a0

DeCoursey, T. E., Chandy, K. G., Gupta, S., and Cahalan, M. D. (1984). Voltagegated $\mathrm{K}^{+}$channels in human $\mathrm{T}$ lymphocytes: a role in mitogenesis? Nature 307, 465-468. doi: 10.1038/307465a0

Egleton, R. D., Brown, K. C., and Dasgupta, P. (2008). Nicotinic acetylcholine receptors in cancer: multiple roles in proliferation and inhibition of apoptosis. Trends Pharmacol. Sci. 29, 151-158. doi: 10.1016/j.tips.2007.12.006

Fiorio Pla, A., Avanzato, D., Munaron, L., and Ambudkar, I. S. (2012). Ion channels and transporters in cancer. 6. Vascularizing the tumor: TRP channels as molecular targets. Am. J. Physiol. Cell Physiol. 302, C9-C15. doi: 10.1152/ajpcell.00280.2011

Fiorio Pla, A., and Gkika, D. (2013). Emerging role of TRP channels in cell migration: from tumor vascularisation to metastasis. Front. Physiol. 4:311. doi: 10.3389/fphys.2013.00311

Hegle, A. P., Marble, D. D., and Wilson, G. F. (2006). A voltage-driven switch for ion-independent signaling by ether-á-go-go K+ channel. Proc. Natl. Acad. Sci. USA 103, 2886-2891. doi: 10.1073/pnas.0505909103

Herrmann, S., Ninkovic, M., Kohl, T., and Pardo, L. A. (2013). PIST (GOPC) modulates the oncogenic voltage-gated potassium channel $\mathrm{K}_{V} 10.1$. Front. Physiol. 4:201. doi: 10.3389/fphys.2013.00201

Huber, S. M., Butz, L., Stegen, B., Klumpp, D., Braun, N., Ruth, P., et al. (2013). Ionizing radiation, ion transports, and radioresistance of cancer cells. Front. Physiol. 4:212. doi: 10.3389/fphys.2013.00212

Improgo, M. R., Soll, L. G., Tapper, A. R., and Gardner, P. D. (2013). Nicotinic acetylcholine receptors mediate lung cancer growth. Front. Physiol. 4:251. doi: 10.3389/fphys.2013.00251

Kondratskyi, A., Yassine, M., Kondratska, K., Skryma, R., Slomianny, C., and Prevarskaya, N. (2013). Calcium-permeable ion channels in control of autophagy and cancer. Front. Physiol. 4:272. doi: 10.3389/fphys.2013. 00272

Leanza, L., Biasutto, L.., Managò, A., Gulbins, E., Zoratti, M., and Szabò, I. (2013). Intracellular ion channels and cancer. Front. Physiol. 4:227. doi: 10.3389/fphys.2013.00227

Lehen'kyi, V., Shapovalov, G., Skryma, R., and Prevarskaya, N. (2011). Ion channels and transporters in cancer. 5. Ion channels in control of cancer and cell apoptosis. Am. J. Physiol. Cell Physiol. 301, C1281-C1289.

Monti, S. M., Supuran, C. T., and De Simone, G. (2012). Carbonic anhydrase IX as a target for designing novel anticancer drugs. Curr. Med. Chem. 19, 821-830. doi: 10.2174/092986712799034851

Munaron, L. (2012). Intracellular calcium signaling: holding the balance between health and disease. Curr. Med. Chem. 19, 5765-5767. doi: $10.2174 / 092986712804143330$ 
Ouadid-Ahidouch, H., and Ahidouch, A. (2013). $\mathrm{K}^{+}$channels and cell cycle progression in tumor cells. Front. Physiol. 4:220. doi: 10.3389/fphys.2013.00220

Pardo, L. A., and Stühmer, W. (2008). Eag1: an emerging oncological target. Cancer Res. 68, 1611-1613. doi: 10.1158/0008-5472.CAN-07-5710

Pedersen, S. F., Hoffmann, E. K., and Novak, I. (2013). Cell volume regulation in epithelial physiology and cancer. Front. Physiol. 4:233. doi: 10.3389/fphys.2013.00233

Rizzuto, R., De Stefani, D., Raffaello, A., and Mammucari, C. (2012). Mitochondria as sensors and regulators of calcium signalling. Nat. Rev. Mol. Cell. Biol. 13, 566-578. doi: 10.1038/nrm3412

Roderick, H. L., and Cook, S. J. (2008). $\mathrm{Ca}^{2+}$ signalling checkpoints in cancer: remodelling $\mathrm{Ca}^{2+}$ for cancer cell proliferation and survival. Nat. Rev. Cancer 8, 361-375. doi: 10.1038/nrc2374

Schuller, H. M. (2009). Is cancer triggered by altered signalling of nicotinic acetylcholine receptors? Nat. Rev. Cancer 9, 195-205. doi: 10.1038/nrc 2590
Yang, M., and Brackenbury, W. J. (2013). Membrane potential and cancer progression. Front. Physiol. 4:185. doi: 10.3389/fphys.2013.00185

Received: 11 October 2013; accepted: 12 October 2013; published online: 29 October 2013.

Citation: Becchetti A, Munaron L and Arcangeli A (2013) The role of ion channels and transporters in cell proliferation and cancer. Front. Physiol. 4:312. doi: 10.3389/fphys. 2013.00312

This article was submitted to Membrane Physiology and Membrane Biophysics, a section of the journal Frontiers in Physiology.

Copyright (c) 2013 Becchetti, Munaron and Arcangeli. This is an open-access article distributed under the terms of the Creative Commons Attribution License (CC BY). The use, distribution or reproduction in other forums is permitted, provided the original author(s) or licensor are credited and that the original publication in this journal is cited, in accordance with accepted academic practice. No use, distribution or reproduction is permitted which does not comply with these terms. 